University of Nebraska - Lincoln

DigitalCommons@University of Nebraska - Lincoln

Faculty Publications, Department of Psychology

Psychology, Department of

January 2007

\title{
Effect of impulsivity on cardiovascular and subjective reactivity to smoking cues
}

\author{
Neal Doran \\ University of Illinois at Chicago, United States \\ Dennis E. McChargue \\ University of Nebraska-Lincoln, dmcchargue2@unl.edu \\ Bonnie Spring \\ Hines VA Hospital, United States
}

Follow this and additional works at: https://digitalcommons.unl.edu/psychfacpub

Part of the Psychiatry and Psychology Commons

Doran, Neal; McChargue, Dennis E.; and Spring, Bonnie, "Effect of impulsivity on cardiovascular and subjective reactivity to smoking cues" (2007). Faculty Publications, Department of Psychology. 270. https://digitalcommons.unl.edu/psychfacpub/270

This Article is brought to you for free and open access by the Psychology, Department of at DigitalCommons@University of Nebraska - Lincoln. It has been accepted for inclusion in Faculty Publications, Department of Psychology by an authorized administrator of DigitalCommons@University of Nebraska - Lincoln. 


\title{
Short communication
}

\section{Effect of impulsivity on cardiovascular and subjective reactivity to smoking cues}

\author{
Neal Doran ${ }^{\mathrm{a}, *, 1}$, Dennis McChargue ${ }^{\mathrm{a}, \mathrm{b}, 2}$, Bonnie Spring ${ }^{\mathrm{a}, \mathrm{b}, 3}$ \\ ${ }^{\text {a }}$ University of Illinois at Chicago, United States \\ b Hines VA Hospital, United States
}

\begin{abstract}
Individuals with high levels of impulsivity are more likely to smoke and may have greater difficulty quitting than other smokers. Although the specific mechanisms mediating this relationship are not explicitly known, one candidate is disproportionate cigarette craving in response to environmental smoking cues. We assessed the effect of impulsivity on three measures of cue reactivity. Regular smokers $(n=75)$ were exposed to a smoking cue and a neutral cue in 2 counterbalanced experimental sessions. Cigarette craving, heart rate (HR), and mean arterial pressure (MAP) were used to index cue reactivity. More impulsive smokers exhibited a disproportionate response to the smoking cue in terms of MAP ( $p=.009)$ but not HR or craving. Impulsive smokers may experience disproportionate cigarette craving in response to environmental smoking cues that are not reflected in self-report measures due to a relative lack of conscious awareness of the urge to smoke.
\end{abstract}

(C) 2007 Elsevier Ltd. All rights reserved.

Keywords: Cigarette smoking; Cue reactivity; Impulsivity

\section{Introduction}

More impulsive people are particularly likely to be regular cigarette smokers (e.g., Kassel, Shiffman, Gnys, Paty, \& Zettler-Segal, 1994) and have greater difficulty quitting (Doran, Spring, McChargue,

* Corresponding author. Building 13, 3rd Floor, 151B, 3350 La Jolla Village Drive, San Diego, CA 92161, United States. Tel.: +1 $8585528585 \times 5587$.

E-mail address: nmdoran@ucsd.edu (N. Doran).

1 Now at the Department of Psychiatry, University of California, San Diego, United States.

2 Now at the Department of Psychology, University of Nebraska, Lincoln, NE, United States.

3 Now at the Department of Preventive Medicine, Feinberg School of Medicine, Northwestern University, Chicago, IL. 
Pergadia, \& Richmond, 2004). Though little is known about mechanisms linking impulsivity and smoking, evidence suggests craving as a plausible candidate. For example, drugs that, like nicotine, increase dopamine (DA) neurotransmission, have been shown to induce disproportionate cravings among impulsive smokers (Reuter \& Netter, 2001).

This is consistent with incentive sensitization theory (IST; Robinson \& Berridge, 1993, 2003), which posits that, through associative learning, events that activate DA release (e.g., drug use) and related cues become particularly salient to substance users. IST holds that chronic drug use leads to sensitization to drug effects and cues, and to neuroadaptations in the mesolimbic DA system. Continued use is thought to lead to more neuroadaptations, promoting further use (Robinson \& Berridge, 2001). These processes may be relevant for impulsive smokers (Reuter \& Netter, 2001), as impulsivity may be linked to reactivity to drug cues (Kambouropoulos \& Staiger, 2001). This study was designed to test the hypothesis that more impulsive smokers are disproportionately reactive to smoking cues.

\section{Methods}

\subsection{Participants}

Demographic and smoking characteristics are shown in Table 1. Participants $(n=75)$ were regular smokers (i.e., at least 15 cigarettes/day for the past year) not currently using nicotine replacement therapy or meeting criteria for other Axis I disorders.

\subsection{Materials}

At baseline, participants completed the Barratt Impulsiveness Scale, version 11 (BIS-11; Patton, Stanford, \& Barratt, 1995). The BIS-11 has been demonstrated to have adequate internal consistency and construct validity (Patton et al., 1995). BIS-11 scores $(M=64.6, \mathrm{SD}=9.9)$ were comparable to those reported for college students and less than those reported for substance abuse patients, psychiatric inpatients, and prison inmates (Patton et al., 1995).

Cue reactivity was measured in terms of craving and cardiovascular function (Table 2). Craving was assessed via the Questionnaire of Smoking Urges (QSU; Tiffany \& Drobes, 1991), which is sensitive to smoking cue exposure (Morgan, Davis, \& Willner, 1999). Craving was assessed at baseline and after $55 \mathrm{~s}$ of cue exposure. Heart rate (HR) and mean arterial pressure (MAP) were also used as cue reactivity indices (Carter \& Tiffany, 1999). HR and MAP were measured via a V72-34 oscillometric blood pressure

Table 1

Sample characteristics

\begin{tabular}{ll}
\hline Variable & Mean (SD) \\
\hline Age & $41.3(10.6)$ \\
Ethnicity & $64 \%$ African-American, 31\% Caucasian \\
Gender & $61 \%$ male \\
Daily cigarette consumption $^{\text {Nicotine dependence }}{ }^{\mathrm{a}}$ & $20.3(6.7)$ \\
\hline
\end{tabular}

${ }^{\text {a }}$ Fagerstrom Test for Nicotine Dependence (FTND; Heatherton, Kozlowski, Frecker, \& Fagerstrom, 1991). 
Table 2

Means (standard deviations) of outcome variables by cue condition and time

\begin{tabular}{lllll}
\hline Variable & Baseline neutral & Post-exposure neutral & Baseline cigarette & Post-exposure cigarette \\
\hline QSU & $15.8(5.9)$ & $18.9(6.0)^{\mathrm{a}}$ & $16.0(6.2)$ & $19.9(6.2)^{\mathrm{a}}$ \\
MAP & $97.7(14.0)$ & $97.8(14.5)$ & $97.8(13.5)$ & $99.9(14.6)^{\mathrm{a}}$ \\
HR & $77.4(10.7)$ & $79.5(11.1)^{\mathrm{a}}$ & $75.9(11.0)$ & $77.8(9.4)^{\mathrm{a}}$ \\
\hline
\end{tabular}

${ }^{\text {a }}$ Significant difference between baseline and post-exposure value $(p<.05)$.

system (Coulbourn Instruments, Allentown, PA). Baseline values were determined by calculating the mean of measurements taken 2 and 4 min after participants began baseline questionnaires. HR and MAP outcome variables were operationalized as the mean of values collected at 0,2 , and 4 min post-exposure.

\subsection{Procedure}

Cue exposure procedures were adapted from Sayette and Hufford (1994). Prior to both the neutral and cigarette cue exposure procedures, participants smoked one of their own cigarettes. During the next $30 \mathrm{~min}$, baseline craving and smoking behavior questionnaires were completed and cardiovascular function were assessed. Participants were then instructed to hold either a roll of tape (neutral cue condition) or a lit cigarette without touching it to their mouths (cigarette cue condition) for 10 min. All participants were exposed to both cue conditions in separate, counterbalanced sessions at least $24 \mathrm{~h}$ apart.

\subsection{Statistical analysis}

Data were analyzed via mixed-effects regression, using linear trends and an uncorrelated variancecovariance structure. Covariates included age, gender, and nicotine dependence. As impulsivity was

Table 3

Mixed effects regression model predicting QSU scores over time

\begin{tabular}{lcrr}
\hline Variable & Regression coefficient & Standard error & $\mathrm{t}$ \\
\hline Time & -31.09 & 24.88 & -1.25 \\
Gender & 9.81 & 9.44 & 1.04 \\
Nicotine Dependence & 3.12 & 2.08 & 1.50 \\
Age & .07 & .43 & 0.17 \\
Cue condition & 1.34 & 4.36 & 0.31 \\
Cue condition $\times$ Time & 61.74 & 28.96 & $2.13^{*}$ \\
Impulsivity & -.50 & .49 & -1.02 \\
Impulsivity $\times$ Time & .84 & .38 & $2.21^{*}$ \\
Impulsivity $\times$ Cue condition $\times$ Time & -.87 & .44 & $-1.98^{*}$ \\
\hline
\end{tabular}

${ }^{*} p<.05 ; * * p<.01$. 
Table 4

Mixed effects regression model predicting mean arterial pressure (MAP) over time

\begin{tabular}{lccr}
\hline Variable & Regression coefficient & Standard error & $t$ \\
\hline Time & .58 & 5.50 & 0.10 \\
Gender & -1.50 & 3.64 & -0.41 \\
Nicotine dependence & .11 & .83 & 0.13 \\
Age & .53 & .20 & $2.64 * *$ \\
Cue condition & -.10 & .99 & -0.10 \\
Cue Condition $\times$ Time & -14.15 & 6.41 & $-2.21^{*}$ \\
Impulsivity & .06 & .18 & 0.32 \\
Impulsivity $\times$ Time & -.01 & .08 & -0.10 \\
Impulsivity $\times$ Cue Condition $\times$ Time & .25 & .09 & $2.62^{* *}$ \\
\hline
\end{tabular}

${ }^{*} p<.05 ; * * p<.01$.

expected to moderate the effect of cue condition on QSU, MAP, and HR over time, we hypothesized significant impulsivity $\times$ condition $\times$ time effects for each outcome.

\section{Results}

\subsection{Craving reactivity}

Mixed-effects regression (see Table 3) indicated that impulsivity moderated the effect of cue condition $\times$ time on craving $[t(195)=-1.98, p=.049]$. We stratified the data and refit the mixed-effects regression model for each condition separately. Impulsivity significantly predicted post-exposure change in craving in the neutral cue condition $[t(65)=2.73, p=.008]$, but not in the cigarette cue condition. In other words, more impulsive participants exhibited a stronger craving response when exposed to a neutral cue but not when exposed to a cigarette cue.

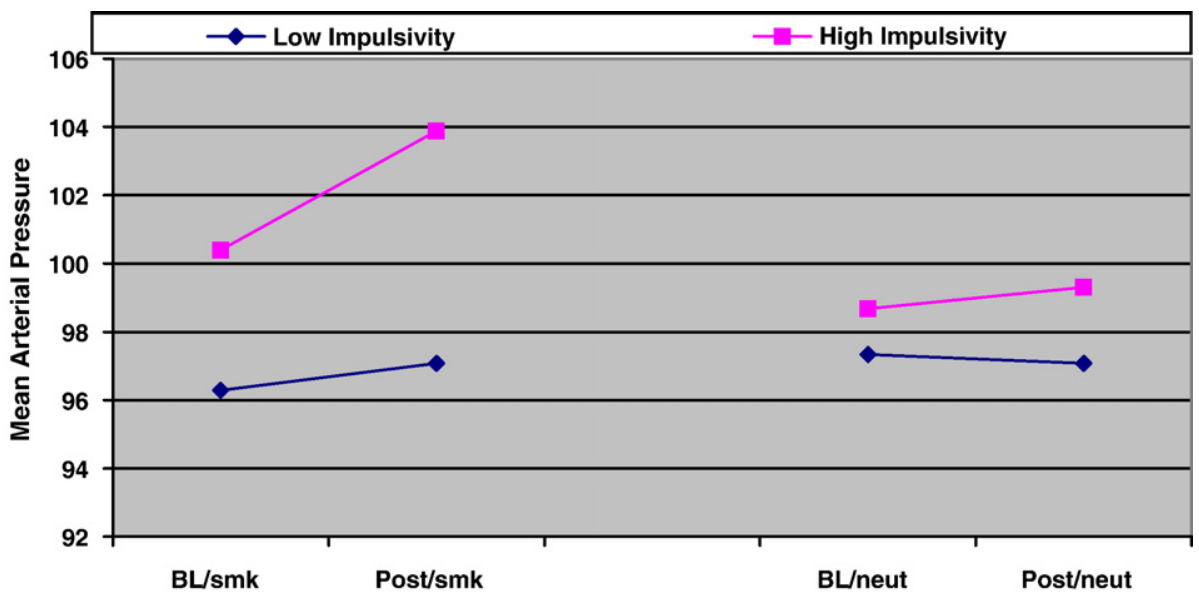

Fig. 1. Mean arterial pressure by time, cue condition, and impulsivity. Note: Impulsivity groups were determined by a median split. BL/smk = baseline MAP, smoking cue condition; Post/smk = post-exposure MAP, smoking cue condition; BL/neut = baseline MAP, neutral cue condition; Post/neut = post-exposure MAP, neutral cue condition. 


\subsection{Cardiovascular reactivity}

Mixed-effects regression analyses (Table 4 ) indicated a significant impulsivity $\times$ condition $\times$ time effect on MAP $[t(167)=2.62, p=.009]$. We stratified the data by condition to examine the effect of impulsivity in each condition (Fig. 1). Impulsivity $\times$ time predicted MAP following exposure to the cigarette cue $[t(64)=2.40, p=.020]$ but not the neutral cue, indicating that more impulsive smokers experienced a greater increase in MAP following exposure to the cigarette cue. The impulsivity $\times$ condition $\times$ time interaction did not significantly predict HR reactivity.

\section{Discussion}

Impulsivity predicted greater reactivity to a cigarette cue in terms of MAP, but not HR or craving. Findings for MAP but not HR support the hypothesis that impulsive smokers experience stronger cardiovascular responses to smoking cues, which may be indicative of approach motivation (e.g., Fowles, 1983; Fowles, Fisher, \& Tranel, 1982). While HR has typically been used to index cardiovascular activity, MAP may also increase in response to reward (Burgess et al., 1993). To the extent that these data indicate disproportionate approach motivation among impulsive smokers when exposed to a smoking cue, such individuals may have greater difficulty inhibiting the urge to smoke in the presence of such a cue.

The finding that impulsivity was independent of HR response to cue exposure was contrary to our hypotheses and inconsistent with the literature (Carter \& Tiffany, 1999). As Piasecki, Smith, and Baker (1999) have pointed out, physiological measures of cue reactivity are not well understood. Consequently, the inconsistent cardiovascular findings in the present study may be explained by an additional variable, or may reflect an indirect connection between cardiovascular activity and cue exposure. The finding that impulsive smokers did not experience stronger cravings in the presence of a smoking cue is also surprising. It was recently suggested that self-reported measures of negative affect are relatively unhelpful outcomes among smokers because much of their processing of negative affective information occurs outside of awareness (Baker, Piper, McCarthy, Majeskie, \& Fiore, 2004). The same argument may also apply in this case. Impulsive smokers may be less aware than others of internal states such as craving, and not reliably report such states; they may tend to respond to craving by smoking immediately, and consequently have difficulty quantifying the state when unable to smoke.

\section{Acknowledgments}

This research was supported by NIDA 1 K08 DA00467 to Dennis McChargue and American Heart Association $0410025 Z$ to Neal Doran.

\section{References}

Baker, T. B., Piper, M. E., McCarthy, D. E., Majeskie, M. R., \& Fiore, M. C. (2004). Addiction motivation reformulated: An affective processing model of negative reinforcement. Psychological Review, 111, 33-51.

Burgess, M. L., Davis, J. M., Wilson, S. P., Borg, T. K., Burgess, W. A., \& Buggy, J. (1993). Effects of intracranial selfstimulation on selected physiological variables in rats. American Journal of Physiology. Regulatory, Integrative and Comparative Physiology, 264, 149-155.

Carter, B. L., \& Tiffany, S. T. (1999). Meta-analysis of cue reactivity in addiction research. Addiction, 94, 327-340.

Doran, N., Spring, B., McChargue, D., Pergadia, M., \& Richmond, M. (2004). Impulsivity and relapse to cigarette smoking. Nicotine \& Tobacco Research, 6, 641-647. 
Fowles, D. C. (1983). Appetitive motivational influences on heart rate. Personality and Individual Differences, 4, 393-401.

Fowles, D. C., Fisher, A. E., \& Tranel, D. T. (1982). The heart beats to reward: The effect of monetary incentive on heart rate. Psychophysiology, 19, 506-513.

Heatherton, T. F., Kozlowski, L. T., Frecker, R. C., \& Fagerstrom, K. O. (1991). The Fagerstrom Test for Nicotine Dependence: A revision of the Fagerstrom Tolerance Questionnaire. British Journal of Addiction, 86, 1119-1127.

Kambouropoulos, N., \& Staiger, P. K. (2001). The influence of sensitivity to reward on reactivity to alcohol-related cues. $A d$ diction, 96, 1175-1185.

Kassel, J. D., Shiffman, S., Gnys, M., Paty, J., \& Zettler-Segal, M. (1994). Psychosocial and personality differences in chippers and regular smokers. Addictive Behaviors, 19, 565-575.

Morgan, M. J., Davies, G. M., \& Willner, P. (1999). The Questionnaire of Smoking Urges is sensitive to abstinence and to exposure to smoking-related cues. Behavioural Pharmacology, 10, 619-626.

Patton, J. H., Stanford, M. S., \& Barratt, E. S. (1995). Factor structure of the Barratt Impulsiveness Scale. Journal of Clinical Psychology, 51, 768-774.

Piasecki, T. M., Smith, S. S., \& Baker, T. B. (1999). Comments on Carter and Tiffany's "Meta-analysis of cue reactivity in addiction research". Addiction, 94, 341-351.

Reuter, M., \& Netter, P. (2001). The influence of personality on nicotine craving: A hierarchical multivariate statistical prediction model. Neuropsychobiology, 44, 47-53.

Robinson, T. E., \& Berridge, K. C. (1993). The neural basis of drug craving: An incentive sensitization theory of addiction. Brain Research Reviews, 18, 247-291.

Robinson, T. E., \& Berridge, K. C. (2001). Incentive-sensitization and addiction. Addiction, 96, 103-114.

Robinson, T. E., \& Berridge, K. C. (2003). Addiction. Annual Review of Psychology, 54, 25-53.

Sayette, M. A., \& Hufford, M. R. (1994). Effects of cue exposure and deprivation on cognitive resources in smokers. Journal of Consulting and Clinical Psychology, 103, 812-818.

Tiffany, S. T., \& Drobes, D. J. (1991). The development and initial validation of a questionnaire on smoking urges. British Journal of Addiction, 86, 1467-1476. 